Machado, M.L.F.; Costa, N.M.C. Ecoturismo e Educação Ambiental no contexto da baixada fluminense: um diagnóstico das escolas do entorno do Parque Natural Municipal de Nova Iguaçu (RJ). Anais do VIII Congresso Nacional de Ecoturismo e do IV Encontro Interdisciplinar de Ecoturismo em Unidades de Conservação. Revista Brasileira de Ecoturismo, São Paulo, v.4, n.4, 2011, p. 547.

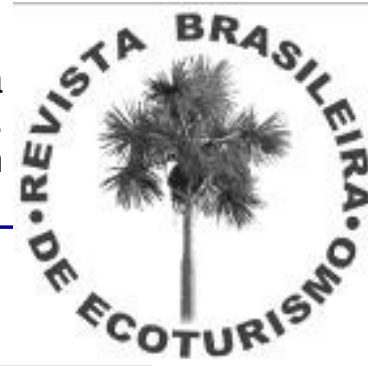

\title{
ECOTURISMO E EDUCAÇÃO AMBIENTAL NO CONTEXTO DA BAIXADA FLUMINENSE: UM DIAGNÓSTICO DAS ESCOLAS DO ENTORNO DO PARQUE NATURAL MUNICIPAL DE NOVA IGUAÇU (RJ)
}

\author{
Márcia Luiza Figueiredo Machado*, Nadja Maria Castilho Costa* \\ *Universidade do Estado do Rio de Janeiro \\ marcialuizafm@terra.com.br, nadjacastilho@oi.com.br
}

A construção de uma proposta pedagógica para as ações de Educação Ambiental (EA) tem grande fonte de contribuição na ciência geográfica. Um bom exemplo dos caminhos alternativos para a sensibilização e mudanças de atitudes é a integração das práticas de EA e de Ecoturismo, em Unidades de Conservação (UCs). Tal proposta orienta os atores sociais envolvidos a definirem as práticas político-pedagógicas que melhor atendam às necessidades da sociedade sustentável. Conhecer e compreender o campo da EA justifica-se, portanto, como uma necessidade primordial para o desenvolvimento de iniciativas e intervenções, de diagnostico ambiental e de gerenciamento e manejo em UC. Em consonância com essa perspectiva, centrase o objetivo desta pesquisa: produzir um diagnóstico que possibilite subsidiar estudos e proposições para cinco escolas da Rede Municipal de Educação de Nova Iguaçu - RJ, situadas na Unidade Regional de Governo Centro, área de influência do Parque Natural Municipal de Nova Iguaçu (PNMNI). A metodologia aplicada constituiu-se de: levantamento bibliográfico alicerçado nas diretrizes estabelecidas nos Parâmetros Curriculares Nacionais (PCNs) e no Plano de Manejo do Parque, acompanhamento semestral das atividades pedagógicas e avaliação das ações de EA desenvolvidas nas escolas enquanto difusoras de conhecimentos e práticas conservacionistas do ambiente local, trabalho de campo e entrevista com o gestor do Parque, aplicação de questionários para a equipe pedagógica e para os professores, visitas e participação nos cursos de formação oferecidos pela Secretaria de Educação. Os resultados obtidos revelaram que os PCNs não são referenciais em muitas escolas, o que pode representar um entrave para as práticas de EA. Além disso, identificamos a falta de suporte material adequado para a realização de atividades de campo. E ainda, as comunidades locais pertencentes às escolas do entorno do PNMNI muitas vezes não tem nesta área protegida o referencial ambiental local para as práticas de EA e ecoturismo. Já sobre o PNMNI, identificamos que o Plano de Manejo, documento basilar na gestão do Parque, é pouco conhecido, como, também, os objetivos dos subprogramas de ecoturismo e educação ambiental. Nesta perspectiva, o diagnóstico realizado através de avaliações investigativas revelou informações importantes que subsidiarão um novo referencial para o tema transversal Meio Ambiente, além de levantar o caráter emergencial da qualificação específica do gestor do Parque, da capacitação do educador e, por conseguinte, da formação do educando, habilitando-o a interagir com o seu entorno imediato, representado pelo PNMNI. Logo, inserir nas escolas o conhecimento sobre o ecoturismo, a partir das ações de Educação Ambiental, e como ele pode ser veículo da conservação ambiental, da inclusão social e da melhoria da qualidade de vida das populações locais, ainda é um desafio que os empreendedores e educadores deverão enfrentar nos próximos anos, principalmente em cidades como a de Nova Iguaçu, com forte potencial e vocação para atividade ecoturística.

Palavras-chave: Educação Ambiental; Ecoturismo; Parque Natural Municipal de Nova Iguacu. 